\title{
Variation of Aerosol Pollution in Peru during the Quarantine Due to COVID-19
}

\author{
Avid Roman-Gonzalez ${ }^{*}$, Natalia I. Vargas-Cuentas ${ }^{2}$ \\ Image Processing Research Laboratory (INTI-Lab), Universidad de Ciencias y Humanidades, Lima, Peru ${ }^{1,2}$ \\ Aerospace Sciences \& Health Research Laboratory (INCAS-Lab), Universidad Nacional Tecnológica de Lima Sur ${ }^{1}$
}

\begin{abstract}
Due to COVID-19, which is a type of pneumonia produced by a coronavirus family virus, the Peruvian government has decreed mandatory social isolation. This isolation is extended until 26 April 2020. Due to this situation, people must stay at home and only go out to make purchases to cover basic needs. This situation, between other things, probably causes pollution reduction that is important for our ecosystem. In Peru, there is not a measurable way to quantify the impact of social isolation on air pollution. The present work aims to show more objectively how much decrease the aerosol pollution in Peru. For this purpose, one uses remote sensing data from Copernicus Data Hub of the European Space Agency, specifically, Sentinel-5 Precursor satellite. The results show an essential reduction of aerosol pollution in different regions of Peru, especially in Lima and the Amazon regions.
\end{abstract} Peru

Keywords-COVID-19; coronavirus; pollution; Sentinel-5P;

\section{INTRODUCTION}

COVID-19 is a disease that started in December 2019 in Wuhan, China [1]. COVID-19 is a type of pneumonia produced by a virus belonging to the coronavirus family that affects the pulmonary alveoli and generates respiratory failure $[1,2]$. According to reports from the World Health Organization (WHO) [3], for 22 April 2020, after China, the outbreak has globally reached 2471136 cases and 169006 deaths. In Fig. 1, one can observe a global map about the impact of the COVID-19 around the World.

Due to the rapid spread of contagion, on 11 March 2020, WHO declared COVID-19 as a pandemic. This declaration was in an opening address by the WHO General Director for a press conference [4].

In Peru, the first case was reported by President Martin Vizcarra at a press conference on Friday, 6 March, 2020 [5]. The evolution in Peru from the first case of COVID-19 has an exponential trend and it is shown in Fig. 2.

Fig. 2 shows the evolution of total cases (curve in blue), new cases per day (bend in gray), total cases recovered (curve in cyan), active cases (line in intense blue), and total deaths (curve in red). Active cases are calculated as the subtraction of the total cases, minus the recovered cases, minus the deceased. Deaths curve is according to right axis, and the other curves are according to left axis. Currently, at 22 April 2020, Peru has 19250 total cases, 7027 recovered cases, 11693 active cases, and 530 deaths.
Due to this situation of the first cases of COVID-19 in Peru and to try to avoid an exponential growth in the number of cases, the President of Peru, Martin Vizcarra, announced the Supreme Decree that declares a State of National Emergency for 15 days [6, 7]. This State of Emergency was reported on March 15, 2020. This declaration implies, among other things, the restriction of the exercise of constitutional rights related to personal liberty and security, the inviolability of the home, and the freedom of meeting and transit in the territory. In this State of Emergency, people are in quarantine; however, the supply of food and medicine is guaranteed.

Although the increase in the number of cases has been somewhat halted compared to projections established with the experience of other countries, the Peruvian government has decided to extend the State of Emergency until April 26, 2020 [8].

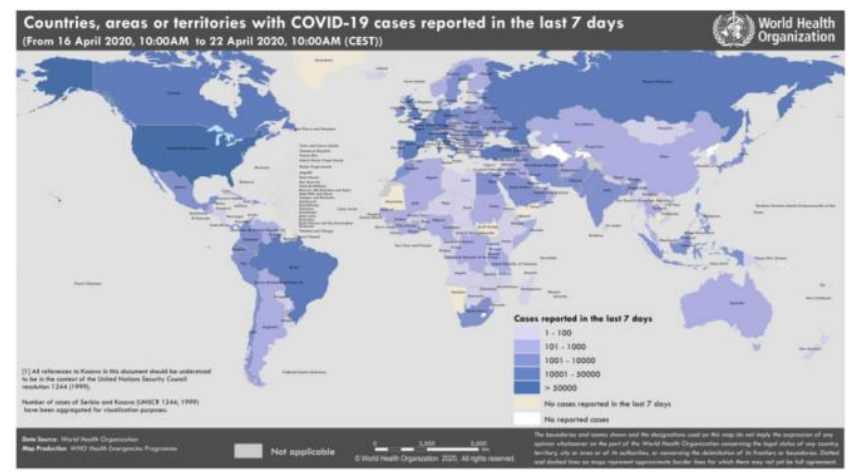

Fig. 1. Countries with Reported Cases of COVID-19, 22 April 2020, (BWHO, [3].

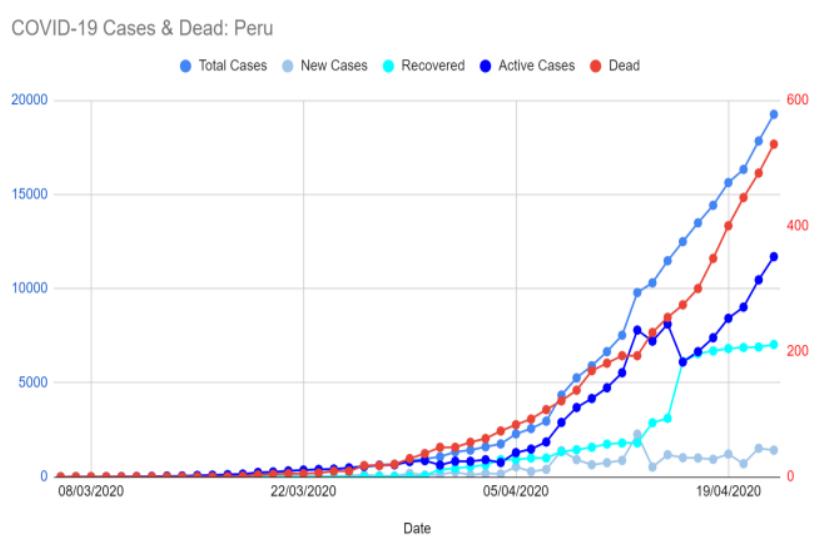

Fig. 2. Evolution of the COVID-19 Cases in Peru, 22 April 2020.

\footnotetext{
*Corresponding Author
} 
In this State of Emergency, people have remained in their homes most of the time. So it has been possible to visualize that the natural ecosystem has recovered. This recovery implies a cleaner sky, clearer waters, return of marine spices to the Sea of Grau, among other aspects [9].

Regarding all the aforementioned, the objective of this work is to measure in a more objective and visible way the reduction of air pollution by aerosols in Peru.

Aerosols are pollutants because they contain substances that, in contact with sunlight, produce polluting gases. Changes in weather may occur. It also affects people's health [10].

Remote sensing is an excellent option to assess air pollution by taking a global view of the area to be analyzed. Measuring aerosols is a good option, as does Gitahi et al. [11], who use high-resolution satellite images such as Sentinel-2 images. In that work, they extract the Aerosol Optical Depth (AOD) from the Sentinel-2 images and compare them with measurements from 2 Aerosol Robotic Network (AERONET) stations for the city of Munich, Germany. The results they obtained show a strong consistency between both analyses, which shows the feasibility of using Sentinel-2 satellite images for this type of purpose.

Another work that uses Lansat- 8 and Sentinel-2 images is the one presented by $\mathrm{Li}$ et al. [12]. In that work, the data obtained from the satellite images are also compared with the data from the AERONET stations. The results they got show that the AOD obtained from the Sentinel-2 images have better precision than the AOD from the Landsat-8 images.

On the other hand, Theys et al. [13] use Sentinel-5 Precursor (also called as Sentinel-5P) images for monitoring volcanic gases.

As can be seen, satellite images can be used effectively in monitoring air pollution, and having a platform to interact and to access images, like the one presented in [14], could be a great help.

The continuation of this research work is as follows, Section II shows the methodology to be followed and the used tool for the analysis, Section III presents the obtained results, and finally, Section IV gives the discussion and conclusions of the work.

\section{METHODOLOGY}

For this research work, one will use satellite images from the Copernicus program of the European Union, specifically Sentinel-5 Precursor (Sentinel-5P) images.

The methodology to be followed will be based on the works presented in $[13,15]$. The idea is to collect a database of images of the region of interest (Peru); read the images and values get from the satellite; finally, mapping the result and compare them.

In the following sub-section, one describes the followed methodology.

\section{A. Sentinel-5 Precursor Images}

Also known as Sentinel-5P, it was launched on October 13, 2017. Sentinel-5P's main objective is the atmospheric monitoring of our planet $[16,17]$.

The Sentinel-5P payload is the TROPOspheric Monitoring Instrument (TROPOMI). TROPOMI is a hyperspectral spectrometer. Fig. 3 is an artistic representation of the satellite Sentinel-5P.

Some specifications of the mission that we can mention are the following $[15,16]$ :

- Sentinel-5P will provide measurements of:

$\begin{array}{ll}\circ & \text { Ozone } \\ \circ & \text { NO_2 (nitrogen dioxide) } \\ \circ & \text { SO_2 (sulfur dioxide) } \\ \circ & \text { Formaldehyde } \\ \circ & \text { Aerosol } \\ \circ & \text { Carbonmonoxide } \\ \circ & \text { Methane } \\ \circ & \text { Clouds }\end{array}$

- Mission Orbit:
- Orbit Type: Sun-synchronous, polar
○ Orbit Height: $824 \mathrm{~km}$

To download Sentinel-5P images and create the database, one uses the Copernicus Open Access Hub of the European Space Agency (ESA). In Fig. 4, one can see a screenshot of the Hub.

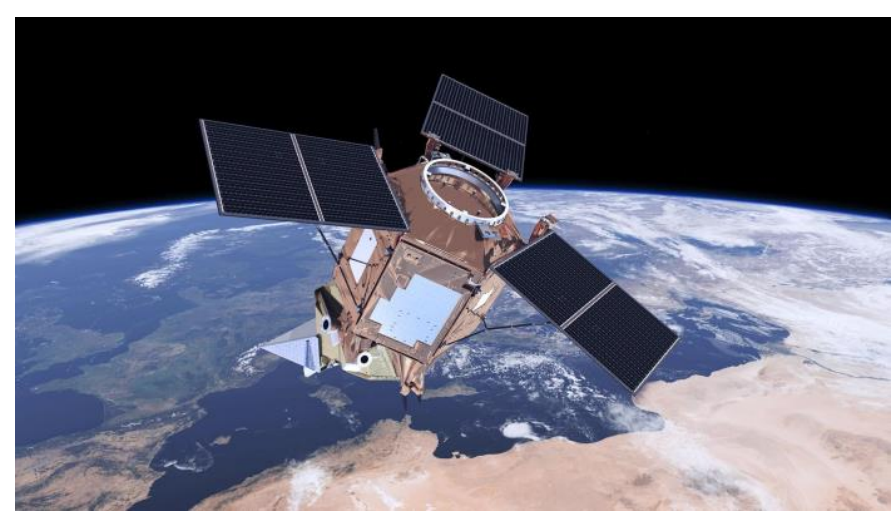

Fig. 3. Sentinel-5P (C) ESA.

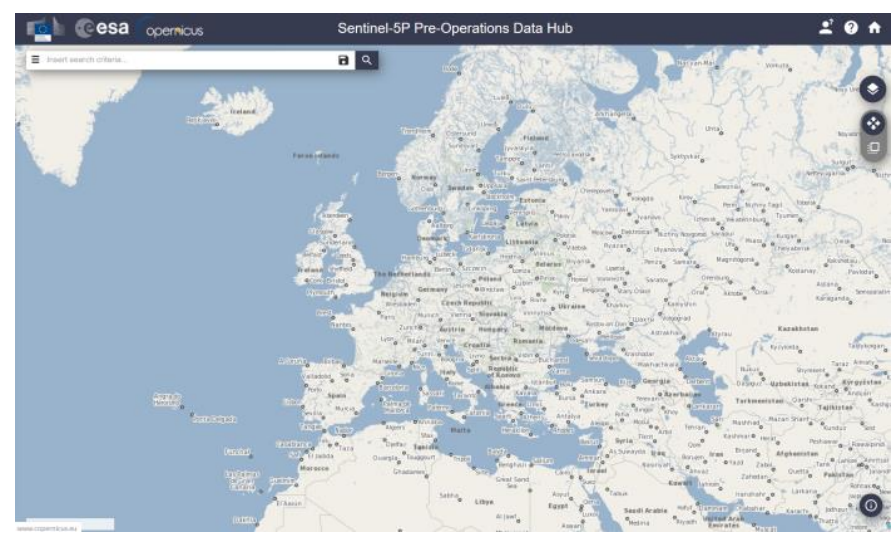

Fig. 4. Copernicus Open Access Hub. 
For the present work, images measuring Aerosol (L2_AER_AI), of the level L2, have been downloaded from March 11 to March 26, 2020. In other words, one has five images before quarantine and ten images during the quarantine.

\section{B. VISAN}

For the processing and visualization of the images, the VISAN tool will be used. VISAN is a cross-platform for visualization and analysis applications for atmospheric data. VISAN uses the Python language as the means through which one can provide commands. The Python interfaces for CODA and HARP are included, so one can directly ingest product data from within VISAN. Also, VISAN delivers some robust visualization functionality for $2 \mathrm{D}$ and world plots [15]. Fig. 5 shows a screenshot of the principal windows of the VISAN tool.

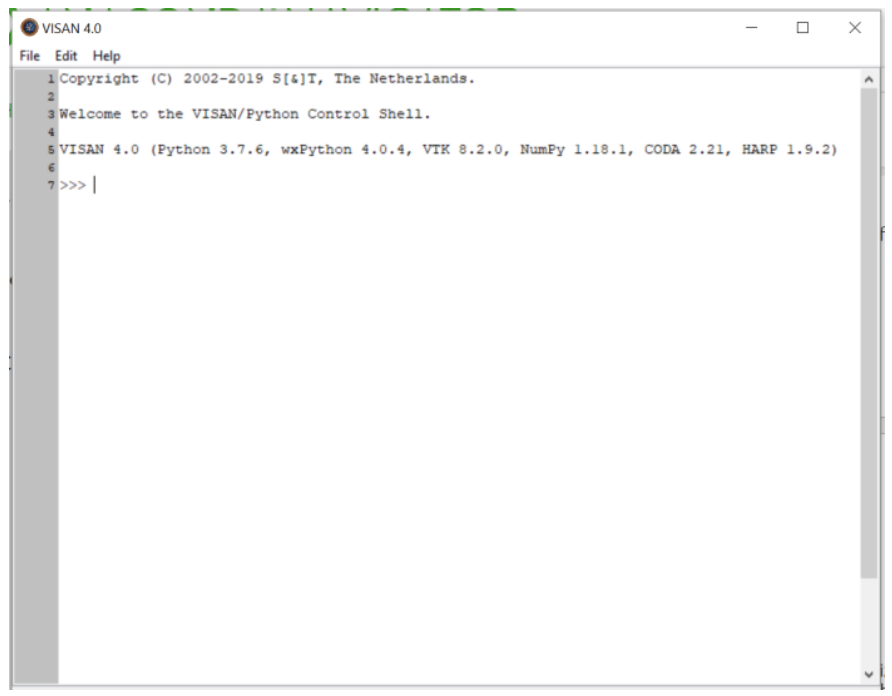

Fig. 5. VISAN Platform.

For this project, the version 4.0 of the VISAN and the version 3.8.2 of Python.

One uses commands like: harp.import_product and wplot among others to read, analyze, and mapping the obtained results.

\section{RESULTS}

After processing and analysis, the visualization can be seen in Fig. 6. It can be seen that before the obligatory isolation measurement, the levels of southern surface wind velocity $(\mathrm{m} / \mathrm{s})$ in Peru had few cyan regions. Ten days after the declaration of a state of national emergency, the cyan areas have increased. Fig. 6 is a heat map where the red zone represents polluted areas, and cyan and blue areas represent areas with less pollution.

The highest levels are seen in shades of red, and the lowest levels are seen in shades of blue.

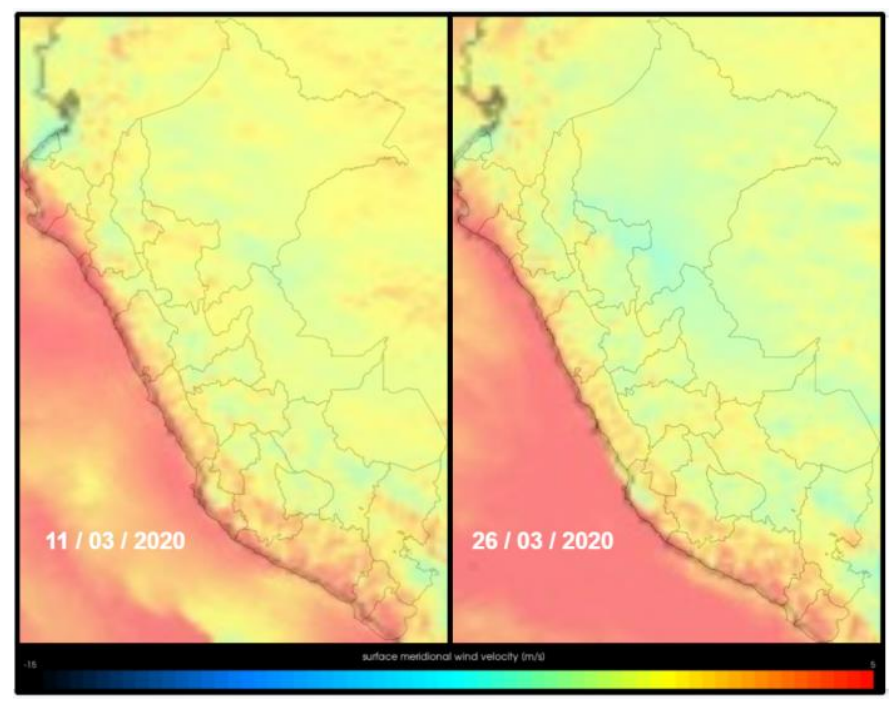

Fig. 6. Variation of Aerosol Contamination in Peru Due to Quarantine by COVID-19.

\section{DISCUSSION AND CONCLUSION}

As can be seen in the results obtained after the processing, analysis, and visualization of Sentinel-5P images, air pollution in Peru during the first ten days of quarantine due to COVID19, has decreased. Some regions have a more significant decrease than others, but in general, a reduction can be noticed throughout the country. This decrease is essential for the planet. As well as in Peru, in other countries, there has also been a decrease in pollution. This situation allows the ecosystem to recover and nature to breathe.

The decrease will be much more noticeable as the days go by, as already mentioned, the quarantine in Peru was extended until April 26.

It is also possible to monitor $\mathrm{SO}_{2}, \mathrm{O}_{3}, \mathrm{NO}_{2}$, Methane, among other parameters. In a future work the idea is to analyse all parameters.

The main contribution of this work is to demonstrate the positive impact of quarantine on the environment objectively.

The evolution of the cases of COVID-19 in Peru shows a small reduction in the trend of change for the last days. New cases per day are around 1000 . In the previous week, there is a slow growth of recovered people, so active cases continue to increase. The increase in the number of cases is also due to the increase in the number of tests, since in Peru molecular tests and rapid tests are currently being used.

\section{REFERENCES}

[1] $\mathrm{Xu}$, Zhe, et al. "Pathological findings of COVID-19 associated with acute respiratory distress syndrome." The Lancet respiratory medicine (2020).

[2] Chen, Huijun, et al. "Clinical characteristics and intrauterine vertical transmission potential of COVID-19 infection in nine pregnant women: a retrospective review of medical records." The Lancet 395.10226 (2020): 809-815. 
[3] World Health Organization. "Coronavirus disease 2019 ( COVID-19): situation report, 93." (2020).

[4] WHO Director-General's opening remarks at the media briefing on COVID-19 - 11 March 2020 [Online] Available at: https://www.who.int/dg/speeches/detail/who-director-general-s-openingremarks-at-the-media-briefing-on-covid-19---11-march-2020

[5] Martín Vizcarra confirmó el primer caso de coronavirus en el Perú [Online] Available at: https://rpp.pe/politica/gobierno/coronaviruscovid-19-gobierno-confirmo-el-primer-caso-en-el-peru-noticia-1249884

[6] Gobierno declaró estado de emergencia por coronavirus en Perú [Online] Available https://larepublica.pe/politica/2020/03/16/coronavirus-peru-martinvizcarra-declara-estado-de-emergencia-nacional-por-30-dias/

[7] Decreto Supremo que declara Estado de Emergencia Nacional por las graves circunstancias que afectan la vida de la Nación a consecuencia del brote del COVID-19 [Online] Available at: https://busquedas.elperuano.pe/normaslegales/decreto-supremo-quedeclara-estado-de-emergencia-nacional-po-decreto-supremo-n-0442020-pcm-1864948-2/

[8] Presidente de Perú anuncia extensión de cuarentena hasta el 26 de abril en busca de frenar el coronavirus [Online] Available at: https://www.americaeconomia.com/politicasociedad/sociedad/presidente-de-peru-anuncia-extension-de-cuarentenahasta-el-26-de-abril

[9] Delfines aparecen en playa La Herradura de Chorrillos tras aislamiento de personas por la cuarentena [VIDEO] [Online] Available at: https://peru21.pe/lima/coronavirus-coronavirus-peru-delfines-aparecen- en-playa-la-herradura-de-chorrillos-tras-aislamiento-de-personas-por-lacuarentena-video-pandemia-coronavirus-covid-19-emergencia-sanitariaestado-de-emergencia-nacional-noticia/

[10] Levin, Z., \& Cotton, W. R. (Eds.). (2008). Aerosol pollution impact on precipitation: a scientific review. Springer Science \& Business Media.

[11] Gitahi, Joseph, Michael Hahn, and Andres Ramirez. "High-resolution urban aerosol monitoring using Sentinel-2 satellite images." Earth Observation and Geomatics Engineering 3.1 (2019): 102-111.

[12] Li, Zhongbin, et al. "Evaluation of Landsat-8 and Sentinel-2A aerosol optical depth retrievals across Chinese cities and implications for medium spatial resolution urban aerosol monitoring." Remote Sensing 11.2 (2019): 122.

[13] Theys, N., et al. "Global monitoring of volcanic $\mathrm{SO}_{2}$ degassing with unprecedented resolution from TROPOMI onboard Sentinel-5 Precursor." (2019).

[14] Roman-Gonzalez, Avid, and Natalia Vargas-Cuentas. "Designing A Web Platform Paradigm for Satellite Images based on user Preferences." 2016.

[15] Serco Italia SPA (2019). Air Quality Monitoring with Sentinel-5p (version 1.1). Retrieved from RUS Lectures at https://ruscopernicus.eu/portal/the-rus-library/learn-by-yourself/

[16] Sentinel-5P [Online] Available at: https://earth.esa.int/web/guest/ missions/esa-eo-missions/sentinel-5p

[17] Zeng, Jian, et al. "Air Quality Satellite Monitoring by TROPOMI on Sentinel-5P." (2018). 